\title{
Learning to read bilingually modulates the manifestations of dyslexia
} in adults

Marie Lallier ${ }^{1,2, *}$, Guillaume Thierry ${ }^{1,4}$, Polly Barr $^{6}$, Manuel Carreiras ${ }^{2,3,5}$ and MarieJosèphe Tainturier ${ }^{1,4}$

${ }^{1}$ School of Psychology, Bangor University, Bangor, UK

${ }^{2}$ Basque Center on Cognition, Brain and Language, Spain

${ }^{3}$ IKERBASQUE. Basque foundation for Science, Spain

${ }^{4}$ Center for Research on Bilingualism, Bangor University, UK

${ }^{5}$ Departamento Lengua Vasca y Comunicación. UPV/EHU. Bilbao, Spain

${ }^{6}$ Department of Cognitive Science, ARC Centre of Excellence in Cognition and its

Disorders, Macquarie University, Sydney, Australia

Word count (excluding abstract and references): 6089 


\begin{abstract}
According to the 'Grain Size Accommodation' hypothesis (Lallier and Carreiras, 2017), learning to read in two languages differing in orthographic consistency leads to a cross-linguistic modulation of reading and spelling processes. Here, we test the prediction that bilingualism may influence the manifestations of dyslexia. We compared the deficits of English monolingual and early Welsh-English bilingual dyslexic adults on reading and spelling irregular English words and English-like pseudo-words. As predicted, monolinguals were relatively more impaired in reading pseudo-words than irregular words while the opposite was true for bilinguals. Moreover, monolinguals showed stronger sublexical processing deficits than bilinguals, and were poorer spellers overall. This study shows that early bilingual reading experience has long-lasting effects on the manifestations of dyslexia in adulthood. It demonstrates that learning to read in a consistent language like Welsh in addition to English gives bilingual dyslexic adults an advantage in English literacy tasks strongly relying on phonological processing.
\end{abstract}




\section{Introduction}

The goal of this study was to examine the potential influence of learning to read bilingually on the long-term manifestations of dyslexia. This question has received little attention so far, even though an ever increasing proportion of children across the world will learn more than one language. In this article we focus on the effects of learning two alphabetic systems that vary in their orthographic depth on the manifestations of developmental dyslexia in adults.

Languages differ in their orthographic properties and there is solid evidence that these cross-linguistic variations influence literacy acquisition and reading/spelling performance into adulthood. Most research has focused on the effect of variations in 'orthographic depth'.

Orthographic depth is a term that refers to the degree of consistency, completeness and/or complexity of orthography-to-phonology mappings in a given language (for a discussion of the different dimensions of this concept, see Schmalz, Marinus, Coltheart, \& Castles, 2015). In shallower orthographies such as Italian, the relationship between graphemes and phonemes is highly consistent. Graphemes are (almost) always associated with the same phonemes, and any variations typically derive from general contextual rules (e.g., $\mathrm{C}->/ \mathrm{s} /$ before I or E but $\mathrm{C}->/ \mathrm{k} /$ before $\mathrm{A}, \mathrm{O}$ and $\mathrm{U}$ ). This means that once the 'code' has been learned it is possible to read words with a high degree of accuracy even in the absence of any lexical knowledge. The relationship between orthography and phonology in deeper orthographies such as English is much less predictable (e.g., $\underline{\text { chip }}$ vs. $\underline{\text { chef }}$ vs. choir). As a consequence, accurate reading requires more than grapheme-to-phoneme (GP) decoding in deeper orthographies.

There is solid evidence that orthographic consistency (or regularity) influences reading processes in children and adults with or without literacy deficits. Learning to 
read appears to be easier and faster in consistent orthographies (e.g., Ellis \& Hooper, 2001; Ellis et al., 2004; Spencer \& Hanley, 2003; Seymour, Aro \& Erskine, 2003; Ziegler et al., 2010). In addition, the manifestations of dyslexia tend to differ (for a review see Sprenger-Charolles, Siegel, Jimenez, \& Ziegler, 2011), with readers of inconsistent orthographies showing relatively more pronounced impairments in processing pseudo-words compared to readers of consistent orthographies (e.g., Talcott, Witton, \& Stein, 2013).

The general interpretation is that learning to read in a consistent orthography favors the awareness of the alphabetic principle (the knowledge that letters represent language sounds), and that the awareness of the alphabetic principle boosts the acquisition of letter-sound associations and of phonological sublexical decoding strategies (Frith, 1986; Liberman, Shankweiler \& Liberman, 1989; Share, 1999). In addition, readers of more consistent orthographies tend to develop better phonemic awareness (Goswami, Ziegler \& Richardson, 2005; Spencer \& Hanley, 2003), an important predictor of deficits in developmental dyslexia (Snowling, 2000; Vellutino et al., 2004), particularly with respect to pseudoword reading disorders (Peterson, Pennington \& Olson 2013, but see Zoubrinetzky, Bielle \& Valdois, 2014). The contribution of phonological awareness to normal and impaired literacy acquisiton is stronger in less consistent orthographies where the relationship between graphemes and phonemes is more complex (Landerl et al., 2013; Ziegler et al., 2010). In other words, phonological reading strategies are harder to master in less consistent orthographies, leading to an increased reliance on the development of lexical strategies and in turn to larger lexicality effects (e.g., Frost, Katz \& Bentin, 1987; Lallier, Valdois, LassusSangosse, Prado \& Kandel, 2014). Lexicality effects (superior performance with familiar words as opposed to new words or pseudo-words) are still present in consistent 
orthographies but are better captured by reading speed due to high accuracy levels (Aro \& Wimmer, 2003; Kirby, Georgiou, Martinussen \& Parrila, 2010; Jiménez, Rodríguez \& Ramírez 2009).

The 'psycholinguistic grain size' theory proposes that orthographic depth modulates the size of the orthographic and phonological functional units upon which reading processes operate (Ziegler \& Goswami, 2005; but see Schmalz, Robidoux, Castles, Coltheart, \& Marinus, 2017). Reading in more consistent orthographies would prompt the use of smaller units (e.g., sublexical units such as letters and phonemes), while inconsistent orthographies would require larger units that could even extend over the whole word form, due to the inherent unpredictability of their GP mappings (Goswami, Ziegler, Dalton, \& Schneider, 2001; Landerl, Wimmer, \& Frith, 1997). Using a large grain strategy would allow English natives with dyslexia to compensate for phonological decoding deficits when reading familiar words. On the other hand, this strategy would put them at a greater disadvantage when attempting to read unfamiliar words.

The grain size theory has mainly focused on the impact of cross-linguistic variations on phonological skills. However, the processing and parsing of letter strings is also dependent on visuo-attentional processes. A critical component is the visual attention span (VA Span), defined as the number of distinct visual elements that can be processed simultaneously in a multi-element array (Bosse, Tainturier \& Valdois, 2007; Lobier, Zoubrinetzky \& Valdois, 2012; Valdois, Bosse \& Tainturier, 2004). The VA span is an independent predictor of children's reading acquisition, particularly in building-up lexical orthographic knowledge and the use of lexical reading strategies (Bosse, Chaves, Largy \& Valdois, 2013; Bosse \& Valdois, 2009; Valdois et al., 2003). Importantly, VA span resources predict the ability to read irregular words independently 
of the role played by phonological awareness (Bosse \& Valdois, 2009). In addition, VA span deficits are thought to cause reading disorders even when phonological awareness skills are preserved (Bosse et al., 2007; Peyrin et al., 2012; Valdois et al., 2003). As would be expected, recent evidence suggests that the contribution of the VA span to reading performance is reduced in more consistent orthographies. Awadh, Phénix, Antzaka, Lallier, Carreiras \& Valdois (2016) showed that the VA Span of skilled adult readers of Spanish (consistent) did not correlate with their reading skills, contrary to what has been reported in inconsistent orthographies such as English and French. In addition, VA span deficits have less impact on reading in consistent orthographies (Valdois et al, 2014). Thus, the size of the VA span and its influence on reading performance appear to be modulated by the optimal grain size of different orthographies. Languages where orthography to phonology conversion operates over smaller units would not need as wide a VA window than languages that require larger units for optimal reading accuracy.

In summary, comparative cross-linguistic studies indicate that orthography to phonology consistency influences the relative strength of sublexical vs. lexical reading strategies and in turn the manifestations of dyslexia in monolingual speakers of different languages. These studies also suggest that the relative importance of phonological awareness vs. visuo-attentional processes is modulated by the orthographic characteristics of different alphabetic systems.

In the current study, we aimed to examine if the manifestations of dyslexia in an inconsistent language (English) would differ for monolingual readers as opposed to bilingual readers having learned to read in a consistent orthography (Welsh) in addition to English. Bilingualism research has flourished in the last few decades, and it has become increasingly clear that bilinguals are not simply two monolinguals in one. 
Indeed, there is accumlulating evidence that the two languages interact with each other at multiple levels in bilingual people. As a result, even when fully proficient, one can observe differences in the way monolingual and bilingual speakers process the same language (Tainturier, in press).

With respect to reading processes, the recent 'Grain Size Accommodation' theory (Lallier \& Carreiras, 2017) offers a framework that allows to predict how bilingualism may interact with reading processes in children and adults with or without dyslexia. The central aspect of the theory is that the processing of different languages in bilinguals is not encapsulated; instead, the theory postulates some degree of transfer to one language of processing abilities that are particularly beneficial to the other. As we have seen, reading in shallower orthographies seems to rely on a smaller grain size than reading in deeper orthographies. In the case of bilinguals, the 'Grain Size Accommodation' hypothesis proposes that the size of both the orthographic and phonological grains used for reading and reading-related tasks in one language is modulated by what is the optimal grain-size in the other.

The 'Grain Size Accommodation' hypothesis is supported by evidence from bilingual readers with and without reading difficulties (e.g., Abu-Rabia \& Siegel, 2002; Da Fontoura \& Siegel, 1995). Recently, the hypothesis was tested more directly in studies conducted with early bilingual adult readers (e.g., Lallier, Carreiras, Tainturier, Savill \& Thierry, 2013) and children (e.g., Lallier, Acha \& Carreiras, 2016). These studies suggest that learning to read simultaneously in a consistent and an inconsistent orthography boosts phonological reading in the inconsistent language and lexical processing in the consistent one (Lallier et al, 2016). In addition, there is evidence for an influence of bilingualism on grain size in skilled adult readers. For example, Lallier et al. (2013) reported a narrower distribution of VA span skills on orthographic strings in 
Welsh-English bilingual readers than in monolingual English controls (see also Lallier et al., 2016). This suggests that individuals having learned to read in a consistent orthography in addition to English tend to use smaller grain strategies even when they perform tasks in their inconsistent orthography.

The 'Grain Size Accomodation' hypothesis also predicts that bilingualism should influence the manifestations of dyslexia. The central prediction is that the severity of the phonological deficits typical of dyslexia in inconsistent orthographies such as English should be reduced in bilingual dyslexic adults having learned to read in both a consistent and an inconsistent orthography. This would be due to a partial transfer of the stronger phonological awareness and sublexical decoding abilities developed as a result of learning a consistent orthography to processing in the less consistent one. A possible downside would be that the size of the VA span may be reduced and that the lexical reading procedure may be less efficient and/or take longer to develop in those bilingual readers. However, it is likely that this relative disadvantage would not last into adulthood, since learning whole-word representations appears to be an automatic process that facilitates reading fluency and comprehension in both consistent and inconsistent orthographies alike. For example, a study of acquired dyslexia in Welsh-English bilinguals showed that the relative preservation of familiar word reading in the face of severe deficits in phonological reading processes was comparable in the two languages (Tainturier, Roberts, \& Leek, 2011). However, differences may become visible with the use of more sensitive measures such as ERPs (Lallier et al., 2013).

The present study 
The goal of this study was to directly test the predictions of the 'Grain Size Accomodation' hypothesis with regards to the manifestations of developmental dyslexia in bilingual adults. To that end, we compared the performance in English tasks of a group of English monolingual dyslexic adults to the performance on the same stimuli of a closely matched group of Welsh-English early bilingual dyslexic adults. These two groups (and their respective non-dyslexic controls) completed a range of tasks designed to assess phonological vs. whole-word reading. The general hypothesis is that the language status of the dyslexic participants will lead to qualitatively different patterns of deficits over and beyond any potential variations in control group performance, in particular with respect to phonological abilities. More specific predictions are presented below following a brief description of the charactersitics of the Welsh orthography.

Welsh-English bilinguals are ideally suited to testing cross-linguistic transfer effects because they learn to read in both a consistent and an inconsistent alphabetic system from an early age. This is in contrast with other bilingual populations that either acquire two relatively transparent orthographies (e.g., Spanish vs. Catalan or Basque), or else different scripts. As Welsh is not a well known language, we will briefly describe its orthography; note that there are some variations between Welsh dialects and that our description specifically applies to northern Welsh. In contrast to English, written Welsh is highly transparent, so much so that Welsh dictionaries do not specify the phonetic equivalent of written words (Ellis \& Hooper, 2001). There are very few exception words in reading, although spelling is somewhat more inconsistent (yet still highly transparent). Thus, virtually all Welsh words can be read successfully via grapheme-phoneme conversion and there is no obvious requirement to develop a sight vocabulary. This readily explains why it is so much easier to learn to read in Welsh than English (Ellis \& Hooper, 2001; Hanley, Masterson, Spencer \& Evans, 2004; Spencer \& 
Hanley, 2003; 2004). Even in those few cases where graphemes can be pronounced in more than one way, the variations are usually context dependent. For example, the letter $\mathrm{Y}$ is pronounced /i/ when it appears in monosyllabic words (except for a few proclitics) or in the last syllable of multisyllabic words; otherwise, Y is pronounced /ə/. Similarly, the sequence SI is pronounced / $/$ / in front of vowels as in 'siop' ('shop') but /si/ in front of consonants or at the end of words (e.g., 'silseg', 'croesi'). Likewise, the letter W corresponds to a glide in front of vowels (e.g., 'wyr', 'gwen') but to the vowel /u/ before consonants (e.g., 'twm', /tum/). In terms of orthographic complexity, Welsh is closer to English, in the sense that it includes a number of digraphs (ch, dd, ff, ng, ll, ph, rh, th). However, these digraphs are treated as single letters even though they include two symbols, and they are included as such in the Welsh alphabet. Thus, "ffrwyth" (/froi $i \theta /$, meaning fruit) is treated as a 5-letter word and consequently would take up only five spaces in a Welsh crossword puzzle. Finally, although Welsh morphology is highly complex in relation to that of English, this does not affect the regularity of orthography to phonology correspondences. For example, if a suffix is added to a word including $\mathrm{Y}$ in its final syllable, its pronunciation changes from $/ \mathbf{i} /$ to $/ \mathrm{\partial} /$ to preserve the contextual rule exposed above, and thus the predictability of its pronunciation.

The central prediction of the current study is that Welsh-English dyslexic participants will show less severe deficits (in relation to non-dyslexic controls) than monolingual dyslexic participants on phonological awareness tasks, and when reading and spelling pseudo-words. As discussed above, this prediction is based on the 'Grain Size Accommodation' hypothesis according to which phonological processing in an inconsistent language may become more efficient and more resilient thanks to the smaller grain size strategies developed while learning the more consistent language. 
The predictions with regards to VA span and lexical reading/spelling are less straightforward. On the one hand, the 'Grain Size Accommodation' hypothesis does state that the two languages would mutually influence each other. Thus, learning to read English in parallel to Welsh should improve larger-grain processing in Welsh (a hypothesis that cannot be tested because virtually all Welsh literate adults are bilingual). The 'Grain Size Accommodation' hypothesis also predicts that the larger grain strategies associated with fluent reading and spelling in an inconsistent orthography such as English may be less effective and/or delayed during reading acquisition if the result of learning to read also in Welsh is to promote an 'intermediary' grain size between Welsh and English. On the other hand, readers of all alphabetic languages must rely on larger grain size and on the memorization of whole-word forms in order to eventually achieve fluent reading and fast mapping between orthography and meaning. This suggests that with sufficient reading experience and practice, the VA span and irregular word reading abilities of Welsh-English bilingual readers should become increasingly close to that of monolingual readers. An open question is whether bilingual dyslexic adults who have suffered specific reading difficulties since childhood would be able to 'catch up' with their lexical reading in the same way that unimpaired readers might. Thus, even though our dyslexic participants were all well-compensated university students, we expected the lexical and VA span deficits to be stronger in the bilingual group. In summary, we predicted that English monolingual dyslexic readers would exhibit a stronger deficit than Welsh-English bilingual participants in phonological awareness tasks, in pseudo-word reading and in pseudo-word spelling. In addition, we expected bilingual dyslexic readers to show a smaller VA span and to be relatively more impaired at reading and spelling irregular words. 


\section{Materials and Method}

\section{Participants}

Sixty adult volunteers (15 skilled monolingual English readers: 4 males, 2 lefthanded, $20.1 \pm 1.5$ years old; 15 skilled Welsh-English bilingual readers: 1 male, 1 lefthanded, $24.5 \pm 7.2$ years old; 15 dyslexic monolingual English readers: 5 males, 4 lefthanded, $20.7 \pm 1.9$ years old; 15 dyslexic Welsh-English bilingual readers: 6 males, 1 left-handed, $24.1 \pm 5.3$ years old) were recruited via the Bangor University's student participant panel and the [name deleted to maintain the integrity of the review process] Dyslexia Unit. Therefore, half of the participants were native speakers of English and considered themselves monolingual. The other half of participants always lived in Wales, learned both English and Welsh between 0 and 5 years of age, and learned to read both in Welsh and English in school, i.e., they had the profile of early WelshEnglish balanced bilingual readers. The study was approved by Bangor University ethics committee and performed in accordance with the ethical standards laid down in the 1964 Declaration of Helsinki. Participants received course and printer credits or financial payment. They all had normal or corrected-to-normal vision, normal hearing, and no history of neurological or psychiatric disorders.

\section{Dyslexia screening in English}

Dyslexic readers were high-functioning young adults with well compensated dyslexia. Allocation to the group of skilled readers or dyslexic readers was based on two criteria: 1) the presence or absence of a previous diagnosis of dyslexia, and 2) the average 
performance on the one-minute reading and the two-minute spelling tasks of the Dyslexia Adult Screening Test (DAST; Fawcett \& Nicolson, 1998). Participants in the control group had no previous diagnosis of dyslexia and obtained an average reading and spelling DAST score above the $23^{\text {rd }}$ percentile. Dyslexic readers had a previous diagnosis of dyslexia and obtained a DAST score below the $23^{\text {rd }}$ percentile. Lastly, for inclusion in the study, participants needed a minimum standardized score of 7 on both the matrix reasoning and the vocabulary subtests of the Wechsler Adult Intelligence Scale $3^{\text {rd }}$ UK (WAIS-IIIUK; Wechsler, 1997).

\section{Task battery}

All the 60 participants undertook a neuropsychological battery allowing us to assess their reading difficulties and the associated cognitive deficits.

\section{Control Tasks}

The Matrix reasoning and the Vocabulary (English Definition) subtests from the WAISIIIUK battery were used to select suitable participants.

\section{General literacy level in English}

In order to assess the general literacy skills of our participants, the one-min reading test and the two-min spelling test of the DAST battery were used. In both tasks, the number of words that the participant could correctly read (or spell) in one (or two) minute(s) was computed. In addition, the nonsense passage reading from the York Adult Assessment battery (Hatcher \& Snowling, 2002) was administered; participants were required to read aloud two passages and the number of errors and time needed to complete the task were recorded.

Item reading and spelling lists in English 
Pseudoword and irregular word reading tasks: The 20 monosyllabic pseudo-words and the 44 irregular English words were taken from Manis, Seidenberg, Doi, McBrideChang, \& Petersen (1996). Participants were asked to read the items aloud as quickly and accurately as possible and the number of errors and time needed to complete the tasks were recorded. These two scores were then converted into a measure of time taken per item (sec/item) and percentage, respectively.

Pseudoword and irregular word spelling to dictation: Twenty irregular words were selected from the list of 44 words of Manis et al. (1996) and matched to twenty pseudowords. For pseudo-words, participants were asked to repeat each stimulus before writing it down to ensure correct perception. If needed, the stimuli were repeated. For both spelling lists, the time needed to complete the task (cumulative time required to write all words) and the number of errors was recorded. These two scores were then converted into a measure of speed (sec/item) and of accuracy (\% correct).

\section{Cognitive abilities}

Phonological awareness: Spoonerisms task (York Battery, Hatcher \& Snowling, 2002).

Participants were required to swap around the initial sounds of spoken names to form new pseudoword pairs (for example 'Sue Kawley' to 'Koo Sawley'). The main task included 12 trials preceded by three practice trials. An accuracy measure (Max $=24)$ as well as the total time required to perform the correct spoonerism trials was recorded. The number of correct words produced per minute was scored. This measure reflects speed as well as accuracy.

Phonological awareness: Phonemic segmentation and spoonerism (DAST).

The task included 12 segmentation items and three spoonerism items. In the segmentation items participants were required to divide words into constituent parts by deleting a syllable or a consonant [e.g., saying "rainbow" without "bow" (i.e., / rain/) or 
saying the first sound of the word "dog" (i.e., $/ d /)]$. For the spoonerisms, the instructions were the same as for the York task. An overall accuracy score was computed (Max = $15)$.

VA span: Partial report

Participants were required to orally report a single cued letter previously presented briefly within a five-consonant string. Fifty five-letter strings were built from ten consonants (upper-case Arial font, 18 pt). The centre-to-centre distance between each adjacent consonant was $1.2^{\circ}$ so that lateral masking effects were minimized. Stimuli did not include the same letter twice and were not English nor Welsh word skeletons (e.g., C M P T R for "computer"). Each letter was used as the target once in each position. A central fixation point was presented for $1000 \mathrm{~ms}$ followed by a blank screen for $50 \mathrm{~ms}$. The five-letter string was then presented at the centre of the screen for $200 \mathrm{~ms}$. At the offset of the letter string, a vertical bar probe appeared for $50 \mathrm{~ms} 1^{\circ}$ below the letter string. Participants were asked to verbally report the cued letter as accurately as possible without time pressure. The score corresponded to the percentage of cued letters accurately reported.

\section{Results}

\section{Control variables and General reading level}

Control variables

A multivariate analysis of variance (MANOVA) was conducted on the control measures of Age, Matrix reasoning and Vocabulary with Group (dyslexia, control) and Language (bilinguals, monolinguals) as between-subject factors. The aim of this analysis was to 
identify control variables on which the four groups could differ. The characteristics of the three groups are provided in Table 1.

\section{[Insert Table 1 about here]}

Results of the MANOVA indicated a main effect of Language (Wilks Lambda=0.95, $F_{(3,54)}=1.03, \mathrm{p}>.05$ ) but no main effect of Group (Wilks Lambda=0.7, $F_{(3,54)}=5.30$, $\mathrm{p}<.005, \eta_{p}{ }^{2}=.23$ ), nor a Group by Language interaction (Wilks Lambda $=0.97, F<1$, p>.05). Univariate results (sigma-restricted) revealed that the bilingual readers were older than the monolingual readers $\left(F_{(1,56)}=9.10, \mathrm{p}<0.005\right)$, and had marginally lower scores on the vocabulary WAIS subtest $\left(F_{(1,56)}=3.10, \mathrm{p}=.08\right)$. The two language groups did not differ on the matrix reasoning subtest $\left(F_{(1,56)}=1.20, \mathrm{p}>.05\right)$. Consequently, the subsequent analyses will include age and vocabulary scores as covariates.

General literacy level

A multivariate analysis of covariance (MANCOVA) was performed on the tasks assessing the general literacy level of participants (1-min reading, 2-min spelling, and nonsense passage reading time and accuracy) with Age and Vocabulary included as covariates. This analysis showed a main effect of Group (Wilks Lambda=0.29, $F_{(4,51)}=31.7, \mathrm{p}<.001, \eta_{p}{ }^{2}=.71$ ), but no main effect of Language (Wilks Lambda=0.95, $F<1, \mathrm{p}>.05$ ) nor a Group by Language interaction (Wilks Lambda=0.96, $F<1, \mathrm{p}>.05$ ). The univariate results confirmed that dyslexic readers performed lower than skilled readers on all of the literacy measures (one-minute reading task: $F_{(1,54)}=38, \mathrm{p}<.001$; twominute spelling task: $F_{(1,54)}=73, \mathrm{p}<.001$; nonsense passage reading time: $F_{(1,54)}=13$, $\mathrm{p}<0.001$ and accuracy: $\left.F_{(1,54)}=66, \mathrm{p}<.001\right)$ measures. Thus, the groups pre-identified as being dyslexic did show significant deficits in relation to controls, confirming their prior diagnosis. Importantly, the size of these deficits did not interact with language, which 
demonstrates that the literacy deficit of the monolingual and the bilingual dyslexic participants was of comparable severity.

Experimental reading and spelling lists

\section{Data Processing.}

In order to compare the deficits of bilingual and monolingual participants, their scores in each task (reading vs. spelling), each stimulus category, and each measure were ztransformed in reference to the scores of their respective control groups. This allowed us to examine the possible effects of bilingualism on the manifestations of dyslexia over and beyond any differences in the performance of the control groups, and also to perform more meaningful comparisons between different tasks, stimuli and measures. Two participants (one in each group) were removed from the reading task analyses due to aberrant scores that were consistent with measurement errors as these participants were not outliers in spelling and in the control measures and diagnostic reading tasks. The z-transformed results are presented in Table 2.

\section{[Insert Table 2 about here]}

\section{Reading}

The results were analysed with a mixed ANCOVA with Group (monolingual vs. bilingual) as the between-subject factor, and Lexicality (pseudo-words vs irregular words) and Measure (Accuracy vs. Speed) as within-subject factors. Age and WAIS vocabulary scores were entered as co-variates. The results of the analysis are clear-cut: The only significant effect was the predicted Lexicality by Group interaction 
$\left(\mathrm{F}_{(1,24)}=6.24, \mathrm{p}=.02, \eta_{p}{ }^{2}=.21\right)$. As can be seen in Figure 1, the monolingual group was severely impaired in pseudoword reading (Estimated marginal Mean $\mathrm{Z}=-3.323,95 \% \mathrm{CI}$ $[-4.546,-2.100]$, in stark contrast with the bilingual group that performed in the low normal range on average (Mean $\mathrm{Z}=-.884,95 \% \mathrm{CI}[-2.107, .339])$.

Furthermore, lexicality had opposite effects in the two groups, with a relative advantage for irregular words in the monolingual group, but for pseudo-words in the bilingual one. Note that both groups can be considered impaired in irregular word reading as they both perform lower than two standard deviations below the mean of their respective control groups (see Figure 1). No other main effects or interactions approached significance (all $\mathrm{p}$ values >.10). Thus, the pattern just described applies comparably to accuracy and speed measurements.

\section{[Insert Figure 1 about here]}

\section{Spelling}

The spelling results were analysed with an ANCOVA following the same $2 \times 2 \times 2$ design as the reading data. This analysis revealed a main effect of Group $\left[\mathrm{F}_{(1,26)}=5.79, \mathrm{p}=.02\right.$, $\eta_{p}{ }^{2}=.18$ ), with no other main effects or interactions approaching significance (all $\mathrm{p}$ values >.10). The main effect of Group reflected the fact that the bilingual participants were less impaired overall than the monolingual participants, irrespective of the lexicality of the items and of the measure taken (Bilinguals: Estimated marginal mean $=-0.805,95 \%$ CI $[-1.503 ;-.106]$; Monolinguals: estimated marginal mean $=-2.03,95 \%$ CI $[-2.729,-1.332])$.

As can be seen in Figure 2, there is a numerical trend towards bilingual spellers being particularly good at pseudo-word spelling. As a matter of fact, they perform in the normal range of bilingual control participants in this condition. It is also noteworthy that 
the performance of monolingual participants is comparable for pseudo-words and irregular words in this task, contrary to reading.

\section{[Insert Figure 2 about here]}

\section{Phonological awareness and VA span}

One of our predictions was that bilingual dyslexic participants would be less impaired than monolingual participants in phonological awareness tasks, but possibly more impaired in VA span tasks. Regarding phonological awareness performance, z-scores obtained on the DAST segmentation task and on the Spoonerism task of the York battery (seconds/word) were entered in an ANCOVA with Task as the withinparticipant factor, Group as the between-subject factor, and Age and Vocabulary as covariates. This analysis revealed no significant effects (all $\mathrm{p}>.10$ ), indicating that the degree of impairment on phonological awareness was comparable for the two groups (Estimated marginal means and confidence intervals: Bilinguals: $\mathrm{M}=-3.40,95 \% \mathrm{CI}=-$ 5.10, -1.70; Monolinguals: $\mathrm{M}=-2.18,95 \% \mathrm{CI}=-3.88,-0.48)$.

Finally, the VA Span of the two groups of participants was estimated using the z-transform of the total accuracy in the partial report task. A one-way ANCOVA with age and vocabulary as co-variates showed no difference between the two groups (Monolinguals: $\mathrm{M}=-0.33,95 \% \mathrm{CI}=-0.97,0.30$; Bilinguals: $\mathrm{M}=-0.74,95 \% \mathrm{CI}=-1.36$, 0.10). The two groups performed in the low average range in relation to their respective control groups. In other words, we did not observe a clear VA span deficit in either group.

\section{Discussion}


This study examined whether or not learning to read in a consistent orthography (Welsh) in parallel to learning to read in an inconsistent orthography (English) would influence the patterns of deficits of Welsh-English bilingual readers with dyslexia, compared to English monolingual readers with dyslexia, when assessed in their inconsistent, hence more difficult, English orthography. Our key findings clearly indicate an influence of language background on the manifestation of dyslexia in adults. Furthermore, our results support specific predictions derived from the 'Grain Size Accomodation' hypothesis. First, bilingual dyslexic participants' deficits in phonologically demanding tasks (pseudoword reading, spelling) were mild in relation to those of monolingual dyslexic participants. Second, the two groups showed reverse lexicality effects. However, the hypothesis that the two groups would differ in phonological awareness and VA span tasks was not confirmed.

It has been repeatedly shown that learning to read in a consistent orthography promotes the development of sublexical decoding strategies and in turn, the development of phonemic awareness, because the mappings between letters and sounds are simple and consistent (e.g., Seymour et al., 2003). Based on evidence that interactions occur between the two languages of bilingual readers (Lallier \& Carreiras, 2017), we hypothesized that the over-reliance on sublexical reading strategies prompted by reading in the consistent Welsh orthography would transfer to English and boost the use of sublexical strategies in this inconsistent orthography too. Therefore, we expected reduced deficits in Welsh-English bilingual readers with dyslexia compared to English monolingual readers with dyslexia on pseudoword reading and spelling as well as phonemic awareness. Several aspects of the results confirmed this hypothesis.

First, the bilingual readers with dyslexia did show a milder pseudoword reading deficit (both on speed and accuracy measures) than their monolingual peers in relation 
to the performance of skilled readers. This suggests that learning to read in the consistent Welsh orthography did indeed reduce phonological decoding difficulties even though these were assessed in the inconsistent English orthography. As a matter of fact, the pseudo-word reading deficit was only significant for the monolingual group, even though the bilingual group also performed worse than the control group. Importantly, we feel confident that this pattern of results reflects the influence of the second language in bilinguals rather than to some uncontrolled factors. The two groups were closely matched on their general literacy level in English; and the fact the the bilinguals had slightly lower scores on a measure of English oral proficiency - Vocabulary subtest of the WAIS battery - was controlled for in all the statistical analyses. Thus, it is plausible to propose that the relatively good English decoding abilities of the bilingual dyslexic group may be due to their experience with Welsh, which boosted sublexical strategies in both languages.

Second, bilingual dyslexic participants showed an overall advantage in spelling tasks, irrespective of stimulus type, that is for both words and pseudo-words. The lack of an interaction between group and stimulus type in spelling can be explained by the fact that spelling, in contrast to reading, strongly engages phonological processes even for real words (e.g., Ramus et al., 2003). One reason for this is that spelling is a more sequential task than reading, due in part to the physical constraints of the auditory and the motor systems. Thus, phonological segmentation, identification and buffering abilities play an important role in producing graphemic sequences, particularly for pseudo-words, but also for real words. We propose that the straightforward sound-toletter conversion rules of Welsh should have helped the bilingual participants to train such processes. This expertise could then be transferred and applied whilst performing English spelling tasks. Although the interaction did not reach significance, there was a 
numerical trend in the direction of a stronger positive effect of bilingualism on pseudoword spelling, as would be expected since irregular word spelling must also rely on language-specific lexical knowledge.

Overall, the results of this study strongly support the hypothesis that learning to read in a consistent orthography in addition to English acts as an important moderator of the severity of the deficits observed in English, especially for phonologicallydemanding tasks. However, orthographic depth factors may not be the sole explanation for the reported effects of bilingualism on dyslexic deficits. Irrespective of orthographic factors, learning two linguistic structures in parralel has been shown to enhance metalinguistic processing skills (e.g., Bialystok, Majumder \& Martin, 2003; Laurent \& Martinot, 2010); this may account for the stronger phonological reading and spelling abilities of our bilingual dyslexic participants. If this hypothesis is correct, similar bilingualism effects might be observed for any language pairs, regardless of the orthographic consistency characteristics of the two languages. However, it is unlikely to be the case for several reasons. First, Lallier et al. (2016) showed that the effects of bilingualism on normal reading acquisition in Basque differ qualitatively as a function of the orthographic consistency of the other language being learned (Spanish vs. French; see also Bialystok, Luk, \& Kwan, 2005). Second, the current study did not reveal any bilingual advantage on phonological awareness skills. Contrary to our a priori predictions, the two dyslexic groups showed comparable deficits on phonological awareness tasks, even though a clear bilingual advantage was observed in phonologically demanding literacy tasks. Interestingly, the predictive power of phonological awareness to reading skills has been shown to significantly decrease along development across alphabetic languages (e.g., Vaessen \& Blomert, 2010). This indicates that although difficulties in phonological awareness may be universal and 
long-lasting in dyslexia, their impact on reading and spelling performance may be reduced in later stages of literacy acquisition. Since our participants were highly compensated university students, the contribution of phonological awareness to their reading and spelling performance may be low as compared to the contribution of other skills such as the automatic use of sublexical decoding conversion rules (boosted by the Welsh consistent orthography).

Lastly, we expected that the lexical and VA span deficits could be stronger in the bilingual dyslexic group, but did not find any difference between the groups on these measures. As mentioned in the introduction, a likely explanation is that readers of both consistent and inconsistent orthographies must eventually rely on larger grain-size processing and on the memorization of whole-word forms in order to achieve fluent reading. Thus, "large grain" difficulties evidenced in bilingual children (e.g., Lallier et al., 2016) may not last into adulthood as bilingual dyslexic eventually 'catch up' because of their extensive reading experience and practice, especially in university student populations. In addition, behavioral measures may not be sensitive enough to capture the potential impact of biliteracy on lexical and VA Span skills. Consistent with this idea, Lallier et al. (2013) reported a bilingualism effect on the distribution of VA Span skills between high functioning English monolingual and Welsh-English bilingual adults, on fine grain ERP measures but not on accuracy or time measures. Overall, further studies are needed in order to explore potential disadvantages on large grain lexical processing in dyslexia, when a consistent orthography is learned in addition to English.

Consistent with our predictions, monolingual and bilingual dyslexic readers showed opposite lexicality effects in reading. Bilingual dyslexic readers had a stronger deficit for irregular words compared to pseudo-words, whereas monolingual dyslexic 
readers showed the opposite pattern (see Figure 1). This suggests that cross-linguistic transfer in Welsh-English bilinguals may 'protect' sublexical reading processes, while the dominant larger-grain processing of English monolingual dyslexic readers would lead to relatively stronger lexical processes. One could argue that these effects can partly stem from the fact that Welsh-English bilinguals had to learn two sets of grapheme-to-phoneme conversion rules, whereas English monolinguals had to deal with a unique set of rules. Indeed, learning two sets of rules may have particularly drawn the attention of bilinguals to the learning of grapheme-to-phoneme conversions rules, and boosted decoding skills in these participants. This scenario is plausible, but unlikel since Lallier et al (2016) showed the opposite effect. French-Basque bilingual readers who learned two sets of grapheme-to-phonemes conversion rules relied more on lexical processes compared to Spanish-Basque bilingual readers who learned only one set of rules and relied more on sublexical strategies. Such evidence supports the role of orthographic consistency in determining the preferred reading strategy used by the participants of the present study.

\section{Conclusions}

This study supports the hypothesis that a cross-linguistic transfer takes place between the languages of bilingual dyslexic readers (Lallier \& Carreiras, 2017). As predicted, dyslexic adults who learned to read in Welsh (a consistent orthography) in addition to English (an inconsistent orthography) showed benefits in literacy tasks engaging phonological processing to a high degree. Overall, this study demonstrates that the language background of dyslexic participants must be taken into account when assessing their deficits both for research and clinical purposes. 


\section{Acknowledgements}

This research was funded by the Fyssen Foundation, the European commission (FP7PEOPLE-2010-IEF, Proposal N²74352, BIRD, to M.L) the European Research Council (ERC advanced grant, BILITERACY, to M.C., and ERC- 209704 to G.T.), the Spanish Government (PSI2015-65338-P to M.L, and PSI2015-67353-R to M.C.), and the Economic and Social Research Council UK (RES-E024556-1 to G.T.). BCBL acknowledges funding from Ayuda Centro de Excelencia Severo Ochoa SEV-20150490 .

\section{References}

Abu-Rabia, S., \& Siegel, L. S. (2002). Reading, syntactic, orthographic, and working memory skills of bilingual Arabic-English speaking Canadian children. Journal of Psycholinguistic Research, 31(6), 661-678.

Aro, M., \& Wimmer, H. (2003). Learning to read: English in comparison to six more regular orthographies. Applied Psycholinguistics, 24(04), 621-635.

Awadh, F. H., Phénix, T., Antzaka, A., Lallier, M., Carreiras, M., \& Valdois, S. (2016). Cross-Language Modulation of Visual Attention Span: An Arabic-FrenchSpanish Comparison in Skilled Adult Readers. Frontiers in Psychology, 7. 307.

Bialystok, E., Luk, G., \& Kwan, E. (2005). Bilingualism, biliteracy, and learning to read: Interactions among languages and writing systems. Scientific Studies of Reading, 9(1), 43-61.

Bialystok, E., Majumder, S., \& Martin, M. M. (2003). Developing phonological awareness: Is there a bilingual advantage?. Applied Psycholinguistics, 24(01), 27-44. 
Bosse, M. L., Chaves, N., Largy, P., \& Valdois, S. (2015). Orthographic learning during reading: the role of whole-word visual processing. Journal of Research in Reading, 38(2), 141-158.

Bosse, M. L., Tainturier, M. J., \& Valdois, S. (2007). Developmental dyslexia: The visual attention span deficit hypothesis. Cognition, 104(2), 198-230.

Bosse, M. L., \& Valdois, S. (2009). Influence of the visual attention span on child reading performance: a cross-sectional study. Journal of Research in Reading, 32(2), 230-253.

Da Fontoura, H. A., \& Siegel, L. S. (1995). Reading, syntactic, and working memory skills of bilingual Portuguese-English Canadian children. Reading and Writing, 7(1), 139-153.

Ellis, N. C., Natsume, M., Stavropoulou, K., Hoxhallari, L., DAAL, V. H., Polyzoe, N., ... et al. (2004). The effects of orthographic depth on learning to read alphabetic, syllabic, and logographic scripts. Reading Research Quarterly, 39(4), 438-468.

Fawcett, A. J., \& Nicolson, R. I. (1998). The Dyslexia Adult Screening Test (DAST): Complete Kit. Psychological Corporation.

Frith, U. (1986). A developmental framework for developmental dyslexia. Annals of Dyslexia, 36(1), 67-81.

Frost, R., Katz, L., \& Bentin, S. (1987). Strategies for visual word recognition and orthographical depth: a multilingual comparison. Journal of Experimental Psychology: Human Perception and Performance, 13(1), 104.

Goswami, U., Ziegler, J. C., Dalton, L., \& Schneider, W. (2003). Nonword reading across orthographies: How flexible is the choice of reading units?. Applied Psycholinguistics, 24(02), 235-247. 
Goswami, U., Ziegler, J. C., \& Richardson, U. (2005). The effects of spelling consistency on phonological awareness: A comparison of English and German. Journal of Experimental Child Psychology, 92(4), 345-365.

Ellis, N. C., \& Hooper, A. M. (2001). Why learning to read is easier in Welsh than in English: Orthographic transparency effects evinced with frequency-matched tests. Applied Psycholinguistics, 22(04), 571-599.

Hanley, R., Masterson, J., Spencer, L., \& Evans, D. (2004). How long do the advantages of learning to read a transparent orthography last? An investigation of the reading skills and reading impairment of Welsh children at 10 years of age. The Quarterly Journal of Experimental Psychology: Section A, 57(8), 1393-1410.

Hatcher, J. \& Snowling, M. J. (2002) York Adult Assessment Battery: An Assessment Battery for Screening Dyslexia in Higher Education. Centre for Reading and Language. Department of Psychology, University of York.

Jiménez, J. E., Rodríguez, C., \& Ramírez, G. (2009). Spanish developmental dyslexia: Prevalence, cognitive profile, and home literacy experiences. Journal of Experimental Child Psychology, 103(2), 167-185.

Kirby, J. R., Georgiou, G. K., Martinussen, R., \& Parrila, R. (2010). Naming speed and reading: From prediction to instruction. Reading Research Quarterly, 45(3), 341362.

Lallier, M., Acha, J., \& Carreiras, M. (2016). Cross-linguistic interactions influence reading development in bilinguals: a comparison between early balanced French-Basque and Spanish-Basque bilingual children. Developmental Science, 19(1), 76-89. 
Lallier, M., \& Carreiras, M. (2017). Cross-linguistic transfer in bilinguals reading in two alphabetic orthographies: The grain size accommodation hypothesis. Psychonomic Bulletin \& Review. doi:10.3758/s13423-017-1273-0

Lallier, M., Carreiras, M., Tainturier, M. J., Savill, N., \& Thierry, G. (2013). Orthographic transparency modulates the grain size of orthographic processing: behavioral and ERP evidence from bilingualism. Brain Research, 1505, 47-60.

Lallier, M., Valdois, S., Lassus-Sangosse, D., Prado, C., \& Kandel, S. (2014). Impact of orthographic transparency on typical and atypical reading development: evidence in French-Spanish bilingual children. Research in Developmental Disabilities, 35(5), 1177-1190.

Landerl, K., Ramus, F., Moll, K., Lyytinen, H., Leppänen, P. H., Lohvansuu, K.. et al. (2013). Predictors of developmental dyslexia in European orthographies with varying complexity. Journal of Child Psychology and Psychiatry, 54(6), 686-694.

Landerl, K., Wimmer, H., \& Frith, U. (1997). The impact of orthographic consistency on dyslexia: A German-English comparison. Cognition, 63(3), 315-334.

Laurent, A., \& Martinot, C. (2010). Bilingualism and phonological awareness: the case of bilingual (French-Occitan) children. Reading and Writing, 23(3-4), 435-452.

Liberman, I. Y., Shankweiler, D., \& Liberman, A. M. (1989). The alphabetic principle and learning to read. In D. Shankweiler \& I. Y. Liberman (Eds.), Phonology and reading disability: Solving the reading puzzle (pp. 1-33). Ann Arbor: University of Michigan Press.

Lobier, M., Zoubrinetzky, R., \& Valdois, S. (2012). The visual attention span deficit in dyslexia is visual and not verbal. Cortex, 48(6), 768-773. 
Manis, F. R., Seidenberg, M. S., Doi, L. M., McBride-Chang, C., \& Petersen, A. (1996). On the bases of two subtypes of development dyslexia. Cognition, 58(2), 157195.

Peterson, R. L., Pennington, B. F., \& Olson, R. K. (2013). Subtypes of developmental dyslexia: testing the predictions of the dual-route and connectionist frameworks. Cognition, 126(1), 20-38.

Peyrin, C., Lallier, M., Demonet, J. F., Pernet, C., Baciu, M., Le Bas, J. F., \& Valdois, S. (2012). Neural dissociation of phonological and visual attention span disorders in developmental dyslexia: FMRI evidence from two case reports. Brain and Language, 120(3), 381-394.

Ramus, F., Rosen, S., Dakin, S. C., Day, B. L., Castellote, J. M., White, S., \& Frith, U. (2003). Theories of developmental dyslexia: insights from a multiple case study of dyslexic adults. Brain, 126(4), 841-865.

Seymour, P. H., Aro, M., \& Erskine, J. M. (2003). Foundation literacy acquisition in European orthographies. British Journal of Psychology, 94(2), 143-174.

Schmalz, X., Marinus, E., Coltheart, M., \& Castles, A. (2015). Getting to the bottom of orthographic depth. Psychonomic bulletin \& review, 22(6), 1614-1629.

Schmalz, X., Robidoux, S., Castles, A., Coltheart, M., \& Marinus, E. (2017). German and English Bodies: No Evidence for Cross-Linguistic Differences in Preferred Orthographic Grain Size. Collabra: Psychology, 3(1), 5.

Share, D. L. (1999). Phonological recoding and orthographic learning: A direct test of the self-teaching hypothesis. Journal of Experimental Child Psychology, 72(2), 95129.

Snowling, M. J. (2000). Dyslexia . Blackwell publishing. 
Spencer, L. H., \& Hanley, J. R. (2003). Effects of orthographic transparency on reading and phoneme awareness in children learning to read in Wales. British Journal of Psychology, 94(1), 1-28.

Spencer, L. H., \& Hanley, J. R. (2004). Learning a transparent orthography at five years old: Reading development of children during their first year of formal reading instruction in Wales. Journal of Research in reading, 27(1), 1-14.

Sprenger-Charolles, L., Siegel, L. S., Jimenez, J. E., \& Ziegler, J. C. (2011). Prevalence and reliability of phonological, surface, and mixed profiles in dyslexia: A review of studies conducted in languages varying in orthographic depth. Scientific Studies of Reading, 15(6), 498-521.

Tainturier, M.J., Roberts, J.R. \& Leek, E.C. (2011). Do reading processes differ in transparent vs. opaque orthographies? A study of acquired dyslexia in Welsh/English bilinguals. Cognitive Neuropsychology, 28, 546-563.

Tainturier, M.J. (in press). A theory of bilingual spelling in alphabetic systems. In C. Perret \& T. Olive (Eds), Studies in Writing, Brill Edition (NL, USA).

Talcott, J. B., Witton, C., \& Stein, J. F. (2013). Probing the neurocognitive trajectories of children's reading skills. Neuropsychologia, 51(3), 472-481.

Vaessen, A., \& Blomert, L. (2010). Long-term cognitive dynamics of fluent reading development. Journal of experimental child psychology, 105(3), 213-231.

Valdois, S, Bosse, M.L., Tainturier, M.J. (2004). The cognitive deficits responsible for developmental dyslexia: Review of evidence for a visual attentional disorder. Dyslexia, 10, 339-363.

Valdois, S., Bosse, M. L., Ans, B., Carbonnel, S., Zorman, M., David, D., \& Pellat, J. (2003). Phonological and visual processing deficits can dissociate in developmental dyslexia: Evidence from two case studies. Reading and Writing, 16(6), 541-572. 
Valdois, S., Peyrin, C., Lassus-Sangosse, D., Lallier, M., Demonet, J. F., \& Kandel, S. (2014). Dyslexia in a French-Spanish bilingual girl: behavioural and neural modulations following a visual attention span intervention. Cortex, 53, 120-145.

Vellutino, F. R., Fletcher, J. M., Snowling, M. J., \& Scanlon, D. M. (2004). Specific reading disability (dyslexia): what have we learned in the past four decades?. Journal of Child Psychology and Psychiatry, 45(1), 2-40.

Wechsler, D. (1997). Wechsler Adult Intelligence Scale (3rd ed.). San Antonio, TX: Psychological Corporation.

Ziegler, J. C., Bertrand, D., Tóth, D., Csépe, V., Reis, A., Faísca, L. et al. (2010). Orthographic depth and its impact on universal predictors of reading a cross-language investigation. Psychological Science, 21(4), 551-559.

Ziegler, J. C., \& Goswami, U. (2005). Reading acquisition, developmental dyslexia, and skilled reading across languages: a psycholinguistic grain size theory. Psychological Bulletin, 131(1), 3.

Zoubrinetzky, R., Bielle, F., \& Valdois, S. (2014). New insights on developmental dyslexia subtypes: heterogeneity of mixed reading profiles. PloS One, 9(6), e99337. 